\title{
ROBOTIC CARE: A LOW COST DESIGN TO ASSIST THERAPY FOR BRAIN STROKE REHABILITATION
}

\author{
Prieto, Pablo (1); Auat, Fernando (2); Escobar, Maria (2); Vallejos, Ronny (3); Maldonado, Paula \\ (4); Larrain, Cristobal (4); Serey, Martin (1) \\ 1: Universidad Técnica Federico Santa María. Engineering Design Department.; 2: Universidad Técnica \\ Federico Santa María. Department of Electronic; 3: Universidad Técnica Federico Santa María. \\ Department of Mathematics; 4: Peñablanca Hospital.
}

\begin{abstract}
A low cost robotic-assisted prototype for finger and hand rehabilitation of people affected by a stroke is presented. The system was developed by a team of undergraduate students led by a Design lecturer in collaboration with the Rehabilitation Unit of the Peñablanca Public Hospital in Chile.

The system consists of a flexion sensor equipped glove, a hand exoskeleton and an Arduino control unit. The patient wears the glove in his healthy hand. When s/he performs movements with the healthy hand, the sensors register the flexion of the fingers and send this information to the servo motors installed in an exoskeleton attached to the affected hand. In this way, the affected hand reproduces the movement of the healthy hand. The system uses a combination of the mirror therapy (the patient sees his/her affected hand moving in the same way that the healthy hand does) and passive exercising (as the exoskeleton produces the movement of the hand affected by the stroke). The combination of two types of therapy in a single low cost system makes the present work unique. In the near future, the developed prototype will be used to validate the effectiveness of the new proposed robotic therapy.
\end{abstract}

Keywords: Open source design, Design for health, Social responsibility, Biomedical design

\section{Contact:}

Prieto, Pablo

Universidad Técnica Federico Santa María

Engineering Design Department

Chile

pablo.prieto@usm.cl 


\section{INTRODUCTION}

Stroke is increasingly impacting the mortality and long-term disability of the world population. In 2013, strokes ware the second most common cause of deaths and the third most common cause of disability (Feigin 2017). One out of 5 people who have had a stroke remain with cognitive and physical sequels, with the motor disability being the most common one. Motor deficits can include weakness, spasticity (continuous muscle contraction), slowness or tremor (Pomeroy 2011), with the upper extremity being affected in about $75 \%$ of stroke patients. As a result, patients are very much dependent on the care of others due to their significantly affected motor performance.

To minimize the impact of stroke sequels, rehabilitation techniques must start as soon as possible. If possible, hours after the stroke. In this way, the therapy can take advantage of the brain plasticity to change neural pathways and synapses as a result of the external stimulation. Traditional therapy includes mirror therapy, electrical stimulation or the passive/active exercising of the affected body part. Some novel techniques have also appeared as stem-cell therapy, repetitive transcranial magnetic stimulation, virtual reality, drug augmentation and robotic therapies (Langhorne 2011). Robotic rehabilitation has shown to achieve significant benefits in terms of functionality, recovery speed and coverage of patients (the person in charge of the robotic system can treat several patients simultaneously).

In this paper we report on the initial stages of the development of a robotic device designed to support the rehabilitation of motor deficit of hands and fingers, in the context of the public health system in Chile. Such context defines important constraints regarding the characteristics of the proposed device. Because brain stroke is the first cause of disability in the Chilean adult population (Moyano 2010), treatment for stroke rehabilitation is a priority in the system. The Health Ministry has set the goal of having $100 \%$ of hospitals of high complexity with the appropriate infrastructure for treatment of stroke and that $100 \%$ of medium and high complexity hospitals provide rehabilitation treatment (Minsal 2014). However, this is a really challenging goal, as the public health service in Chile serves about $85 \%$ of the population but it has severe problems in terms of human and economic resources: less than $50 \%$ of doctors work in the public system and the percentage of the GDP spent on the public health system is 7.2, below the average OCDE spending (Goic 2015). Besides, the Chilean public health system currently has only 2 specialized hospitals in stroke rehabilitation.

In this context, we have been working on the initial stage of a stroke rehabilitation robotic-assisted system. The proposed system differs from the current commercial alternatives in the following aspects:

- Low cost: Commercially available systems are expensive. For example, ReoGo -that provides a single therapy focused on upper limbs - has an approximate cost of USD 90,000 (Motorika 2019). Due to the economic constraints of some countries, a low cost alternative is required to achieve the massive coverage defined by Health Ministries.

- Simultaneous therapies (mirror therapy and passive exercise): The proposed system has the advantage of providing two different therapies simultaneously, which might help to increase the benefits of the rehabilitation treatment

- Flexible and adaptable exoskeleton : Due to the differences in the anthropometric characteristics of different populations, the system has been designed to facilitate its adaptation to different patients. By being built using textile materials, it provides flexibility and comfort.

- Monitoring capability: the final system is envisaged to be equipped with a software platform that monitors the therapy exercises performed by each patient as well as the time devoted to them.

In this paper we present the development of the first and second prototypes of this robotic-assisted rehabilitation system. The project was the result of a collaborative agreement between the Peñablanca Hospital and the Engineering Design Department at Universidad Técnica Federico Santa María and benefitted from further collaboration with the Electronic Engineering Department of the same university.

\section{ROBOTIC-ASSISTED STROKE REHABILITATION}

Systematic reviews on the effects of robotic-assisted therapy on stroke patients have shown they have greater benefits on patient recovery than just conventional therapy (Norouzi-Gheidari 2012, Kwakkel 
2008). The same results have been found for the specific case of hands and finger rehabilitation (Fischer 2007).

For robotic rehabilitation of hands and fingers, the following aspects must be considered:

- A handicapped hand has a significant weakness in the flexion of fingers and the extension of muscles (Lambercy 2007, Kwakkel 2003). Thus, exoskeletons for hands must be designed to perform repetitive actions that require flexion/extension of fingers and muscles, such as grasping and manipulating objects (Brokaw 2011, Iqbal 2011, Carey 2007, Fischer 2007, Lelieveld 2006, Folgheraiter 2005, Tzafestas 2003, JACE Systems).

- A rehabilitation device for hands should allow the palms to be free, so patients can still interact with objects. Due to this restricted space for hand movements, most of the exoskeletons are operated remotely using actuators located in a central unit. Torque and force are transmitted to the mechanisms of the exoskeleton through Bowden cables or tendons with as less friction as possible, as those presented in (Nef 2009, Hidler 2005, Lum 2002, Fanin 2003). However, such configuration limits the degrees of freedom of the device. In (Sarakoglou 2004) a system with 7 degrees of freedom is proposed, although at least 2 degrees of freedom have been proposed as a minimum (Ochoa 2000). In (Wege 2005) tendons where replaced by motors. (Bouzit 2002) proposes a pneumatic device located in the palm of the hand. Although the device still offers good results regarding maneuverability, it does not allow the patient to manipulate objects. Other works in the same line are (Wang 2009, Ochoa 2009).

- Portability is another important aspect, as a portable device can be used as prosthesis for training and rehabilitation but also as an assistance tool in daily tasks. The latter leaves out a lot of developments that focus only in rehabilitation without promoting patient independence (Wang 2009, Ochoa 2009, Iqbal 2015).

- Efficient human-machine interaction, in such a way that the system is ergonomic, friendly to the user, easy to install and includes the patient as part of the system, and not as a separate entity to the robot (Duschau-Wicke 2010).

Regarding patents, a preliminary search allowed us to identify the following proposals:

- CN 203935386 U: "Exoskeleton type upper limb rehabilitation robot"

- CN 102151215 B: "Exoskeletal rehabilitation mechanical arm for upper limb"

- CN $204147236 \mathrm{U}$ : "Wearable exoskeleton hand function rehabilitation trainer"

- $\quad$ CN 102895091 B: "Wearable portable power exoskeleton hand function rehabilitation training device"

- WO 2015047070 A1: "Orthotic device for assisting with bending and extending movements of the fingers of a patient suffering from paralysis of the brachial plexus"

These documents describe several exoskeletons for hand rehabilitation with similar technologies. However, unlike our proposal, they do not consider simultaneous therapy techniques or adaptability to different hand sizes in a simple way.

Regarding commercial products currently available, we can mention:

- Bioness H200 Wireless Hand Rehabilitation system

- MediTouch HandTutor physical therap (http://www.meditouch.co.il/en)

- BiMeo PRO (http://www.kinestica.com/)

- MusicGlove Hand Rehabilitation System (https://www.flintrehab.com/)

These use auxiliary systems such as interaction with multimedia applications, for encouraging patients to perform a specific type of exercise (active exercise therapy).

There are also robotic systems which use active exercise and electro stimulation, such as "The Hand of Hope" (http://www.rehab-robotics.com/), which electrically stimulates the muscles while a control system activates an exoskeleton, which performs and transfers the movements of the hand. Finally, there are also passive exercise systems such as "AMADEO - Five Fingers" (http://tyromotion.com/en/products/amadeo), which uses an exoskeleton system to perform pre-established movements for neuronal stimulation.

\section{THE PROPOSED SOLUTION}

The proposed robotic system combines mirror and passive exercise therapies in order to support the rehabilitation process of patients with motor deficit in fingers and hands resulting from a stroke. 
Mirror therapy is a well-known therapy with reported success (Paik 2014). During the therapy, a mirror is placed in front of the healthy limb. The affected limb is behind the mirror, as shown in Figure 1, and the patient cannot see it. When the patient looks at the mirror, what they see is the reflection of their healthy limb taking the place of the affected limb. This creates a visual illusion: when moving the healthy hand, the patient sees/believes that they are moving the affected hand as well (Rothgangel 2011).

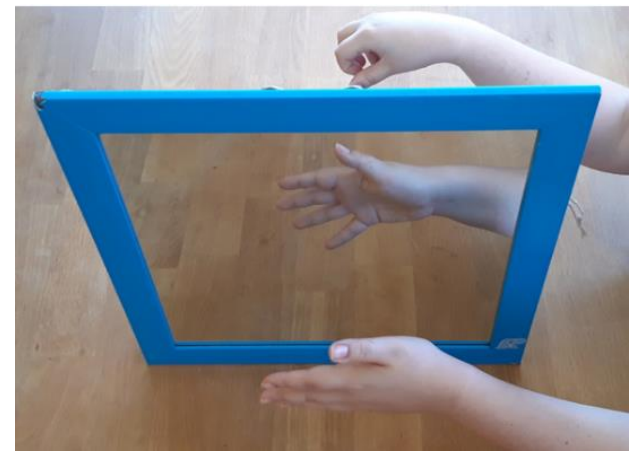

Figure 1. Mirror therapy

In passive exercise therapy, the therapist helps to perform repetitive movements with the affected limb. In this line, robotic-assisted systems have been used - for more than a decade already - with very positive results (Susanto 2015, Taheri 2014, Loureiro 2011, Prange 2006, Lum 2002). In this type of systems, the rehabilitation professional or specialized software controls the movement induced by the robot.

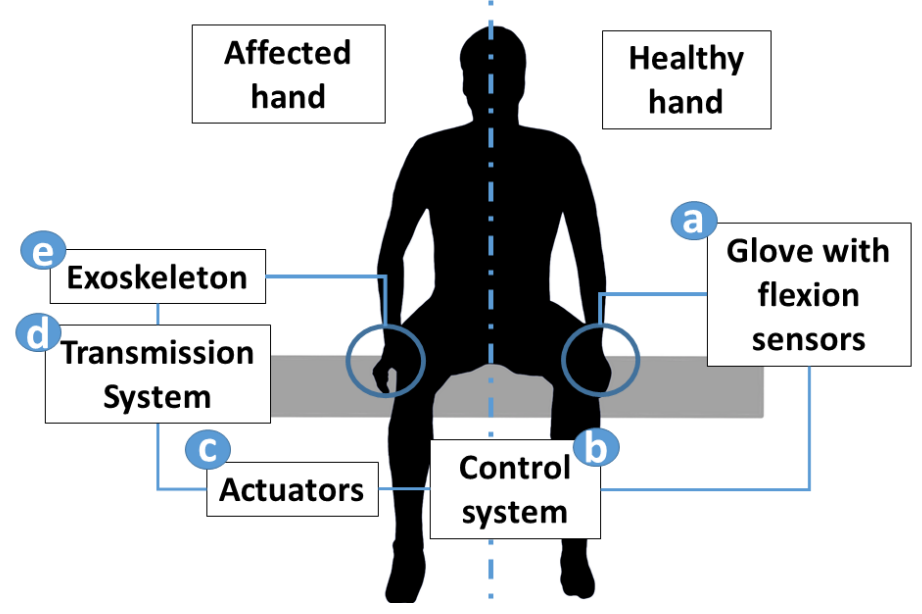

Figure 2. a.-Glove with flexion sensors built in, b.- Electronic control system, c.- servo motors and transmission system $d$.- Exoskeleton that move the affected fingers.

Figure 2 shows the schematic of the proposed system, composed of a glove with flexion sensors, used on the healthy limb (a). When making claw movements with the healthy limb, the degree of flexion of each finger is transmitted to a control system (b), which in turn transmits the corresponding signals to a set of servo motors or actuators (c) that through a transmission system (d) move a 5-finger tensorbased exoskeleton (e) placed on the affected limb. In this way, each finger of the exoskeleton mimics the movement performed by the fingers of the healthy limb. Therefore, without the need of a mirror, the patient can see how the affected limb performs the movements aided by the exoskeleton driven by the healthy hand.

The main contributions of the proposed system, compared to other solutions currently available in the market, such as the "AMADEO - Five Fingers" system (http://tyromotion.com/en/products/amadeo), is the simultaneous application of two therapies that are normally performed separately (mirror therapy and passive exercise) and the low cost. 


\section{THE PROTOTYPE SYSTEM}

The first prototype was developed in the context of an undergraduate course focused on Product Development by a team of 6 students. The student team was guided by a Design lecturer, two medical doctors, and a lecturer from the Electronic Engineering Department. The medical doctors, coming from a public hospital providing stroke rehabilitation, gave to the students and lectures specialized feedback during course.

Figure 3 shows the first functional prototype being used by a healthy person. The white glove is equipped with flexion sensors and the person must wear it on their healthy hand. Figure 4 shows the details of the first prototype: the sensor glove that is used in the healthy hand (a), the control system with the actuators inside a case (b) the transmission system (c) and the exoskeleton (d). The prototype electronic system was built using an Arduino platform. The transmission system was implemented by using bicycle brakes transmission parts. The case as well as the different parts of the exoskeleton were fabricated using laser cutters and FDM low cost additive manufacturing technology.

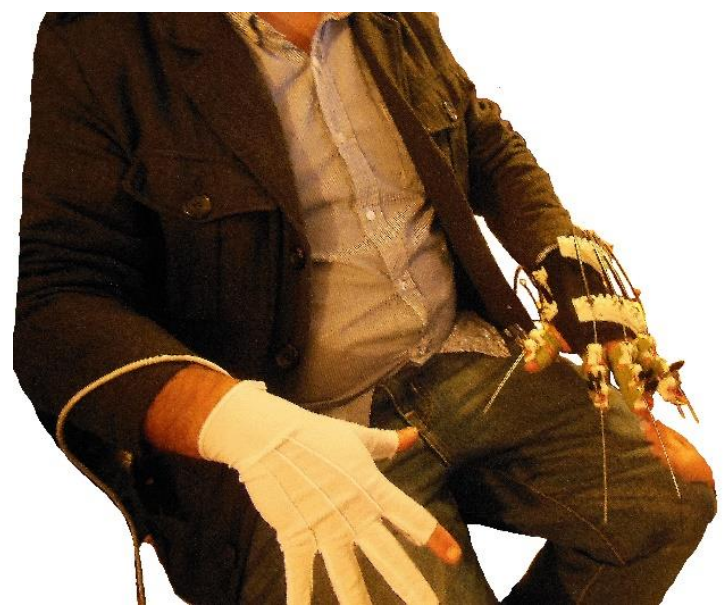

Figure 3. The first prototype system being used by a healthy person

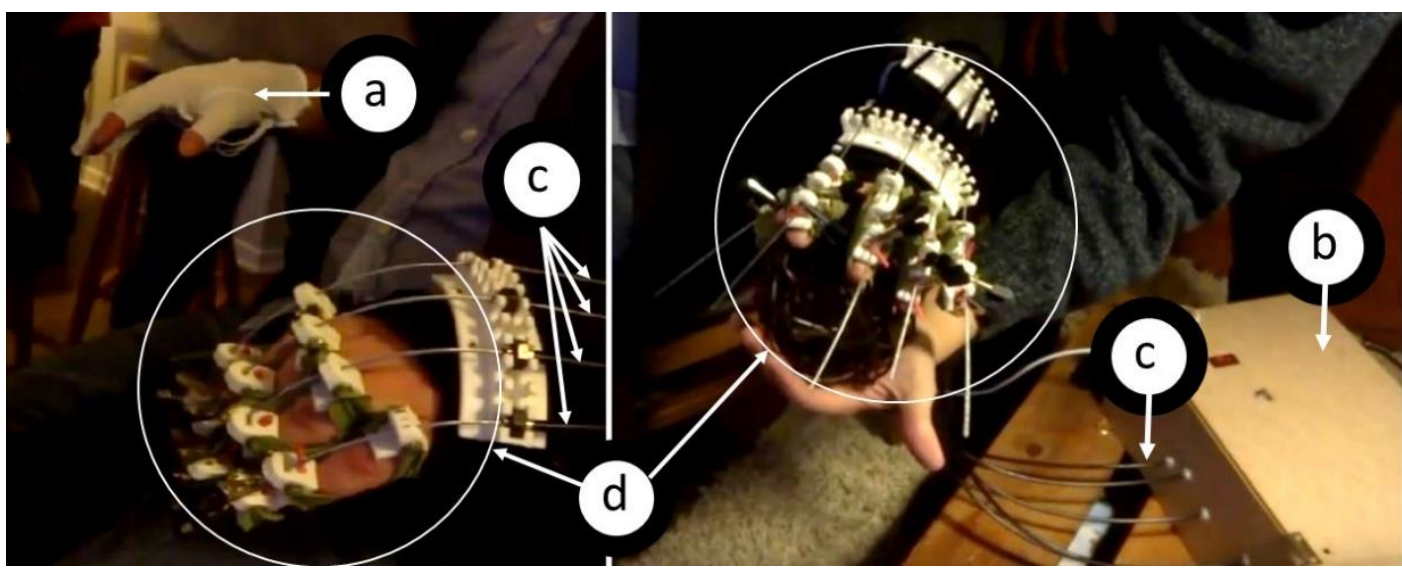

Figure 4. a) glove with the flexion sensors b) control system c) transmission system and d) exoskeleton

After the medical doctors tested the first prototype and gave positive feedback, a second prototype was built by one of the students from the original team who continued with this work as part of his final year project. This student developed a second prototype supported by a multidisciplinary team, composed by professionals from kinesiology, psychiatry, design and robotics.

Figure 5 shows the second prototype. The entire system was conceived as a unit made of 4 distinguishable parts: the sensor glove, the control/transmission system, the calibration system and the exoskeleton.

The sensor glove: the sensor glove of this prototype is not significantly different from that of the first prototype, except for the glove material (in the second prototype the glove is made of leather).

The control/transmission system: The control and transmission system was redesigned and fitted inside a transparent box. Part of the transmission system (cables) is naturally outside the box. As in the 
first prototype, the system is made of an Arduino platform that receives the signals from the flexion sensors; processes them and then activates the servomotors accordingly, for them to move the cables that control the exoskeleton. The servomotors used have a 180-degree movement range. Across this range, force is not uniformly applied if the default servo arms, are directly used to fix the transmission cables. In the first prototype, this resulted on a non-smooth movement of the exoskeleton as the cables were connected directly to one extreme of the servomotor arm. To make sure that the force applied by the motors is uniformly distributed across their 180-degree range and thus, a fluid movement of the exoskeleton could be achieved, 3D-printed compensating cylinders were installed on top of the motors. The top of these cylinders can be seen in Figure 5. Figure 6 shows a lateral, closer view of one of them.

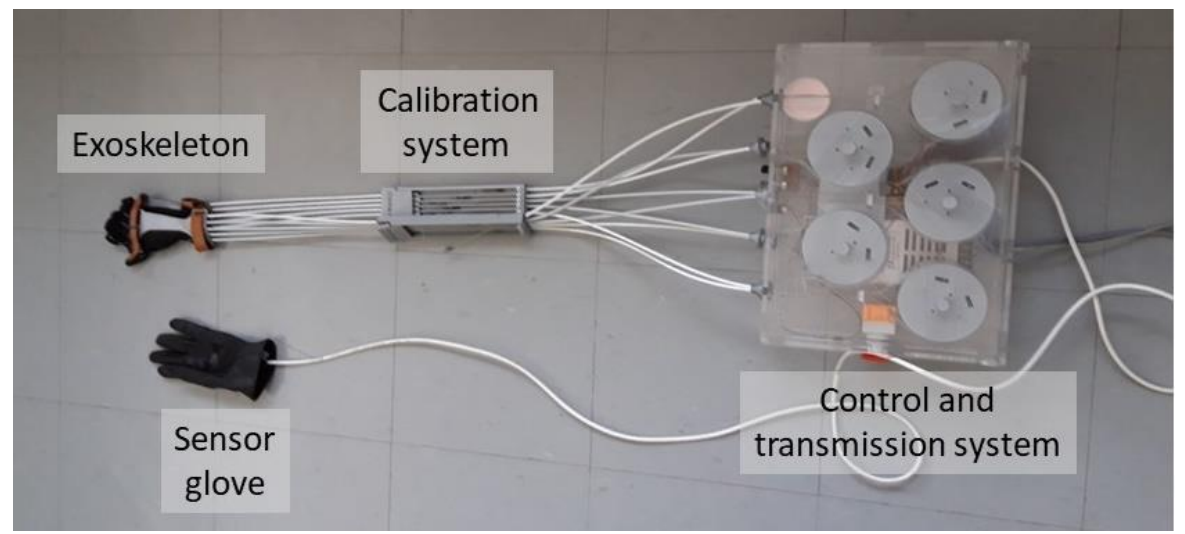

Figure 5. The general configuration of the second prototype.

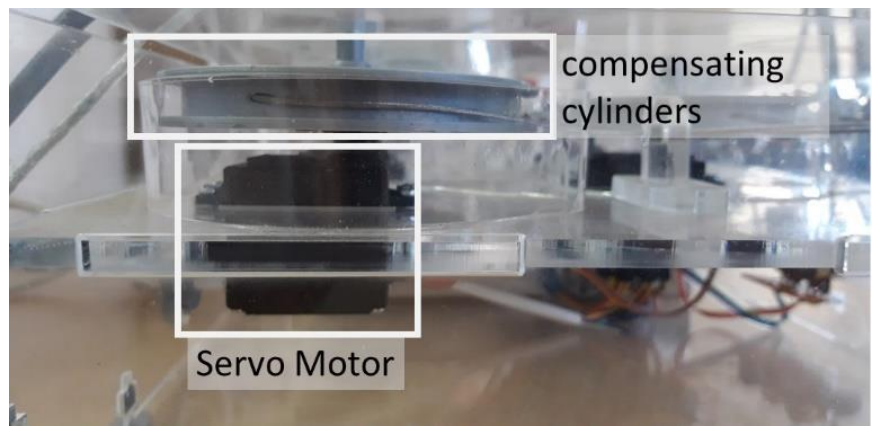

Figure 6. A close up view of a servomotor equipped with a compensating cylinder

Figure 7 shows a closer view of the box containing the control system. Figure 7 left, shows an upper view of the box, where the location of the servomotors can be observed. Figure 7 right shows the lower part of the box, where the following can be observed: a partial view of the set of servomotors (a), the electronic control system (b), the power supply (c) and an emergency stop switch (d).
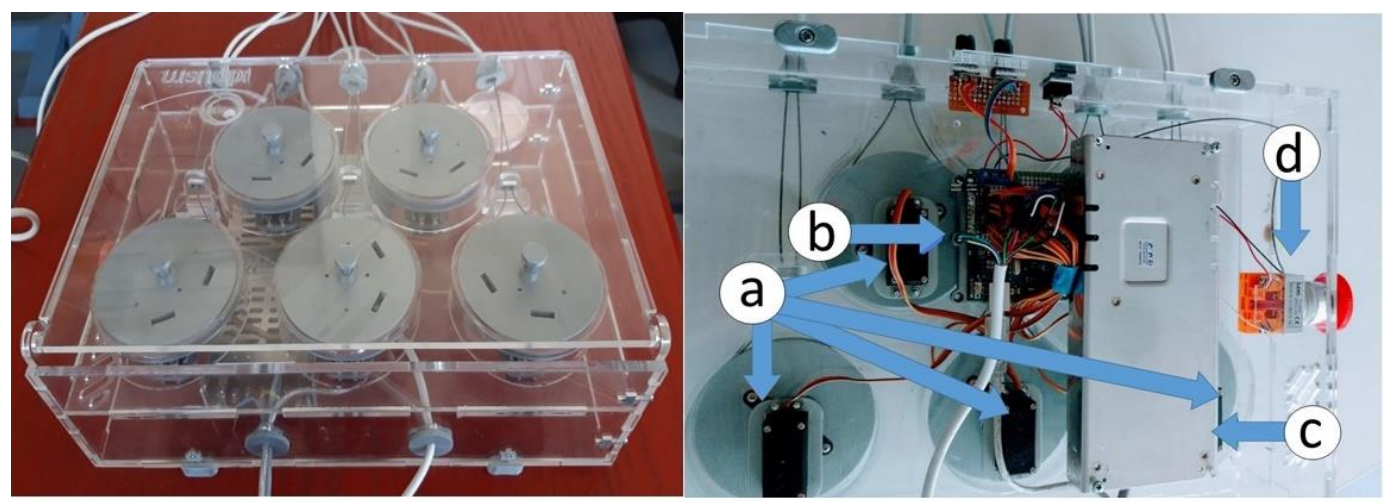

Figure 7. Left: Upper view of the control system. Right: Lower view of the control system showing the distribution of servos (a), electronic parts (b), power supply (c) and emergency stop switch (d) 
The exoskeleton: From the user point of view, the most important improvement carried out in the second prototype is the exoskeleton. This was redesigned to have a smaller size, so the user can have the feeling of wearing an ordinary glove instead of an external structure attached to the hand. To do so, the original wires in charge of bending the fingers by pushing from the external part of the hand, were replaced by much thinner threads that go around each finger. They work like tendons and are integrated into a glove, as shown in Figure 8. In the new configuration, the thin integrated threads pull the fingers to close and open the hand. When the hand opens, the threads located outside the hand pull the fingers to stretch them and achieve the opening movement. When the hand closes, the threads located inside of the hand are pulled to achieve the closing movement.

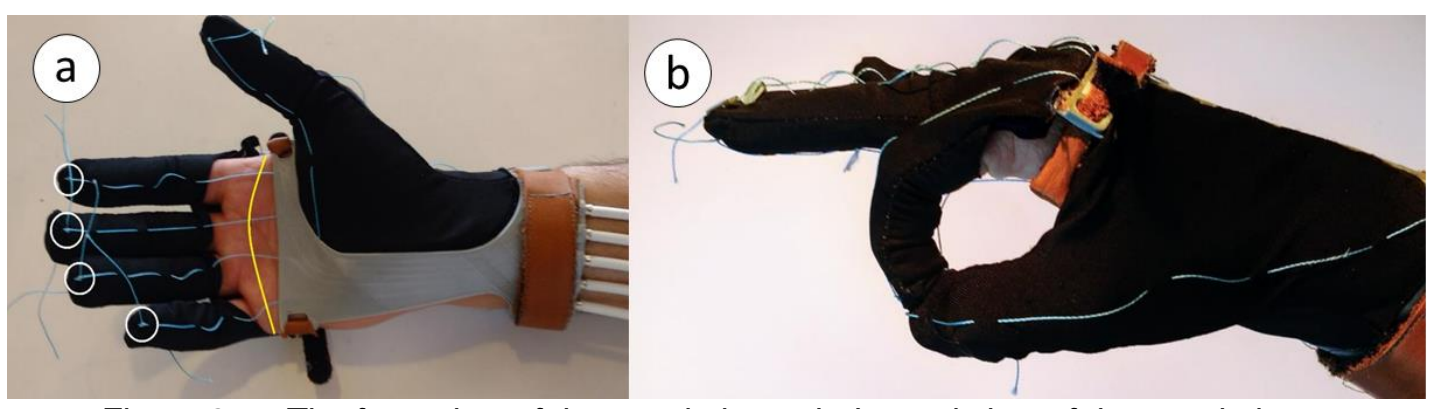

Figure 8. a. The front view of the exoskeleton. b. Lateral view of the exoskeleton.

The calibration system: This is a further improvement made to the second prototype. The calibration system function is twofold. Firstly, it is used to adapt the length of the threads to the hand size of the patient. Figure 9 shows a closer view of this part. Secondly, through the movement of knobs (see Figure 10) the speed of the exoskeleton movement transmitted to the fingers can be adjusted as well as and the initial position of it (e.g. fully stretched fingers or fully closed hand).

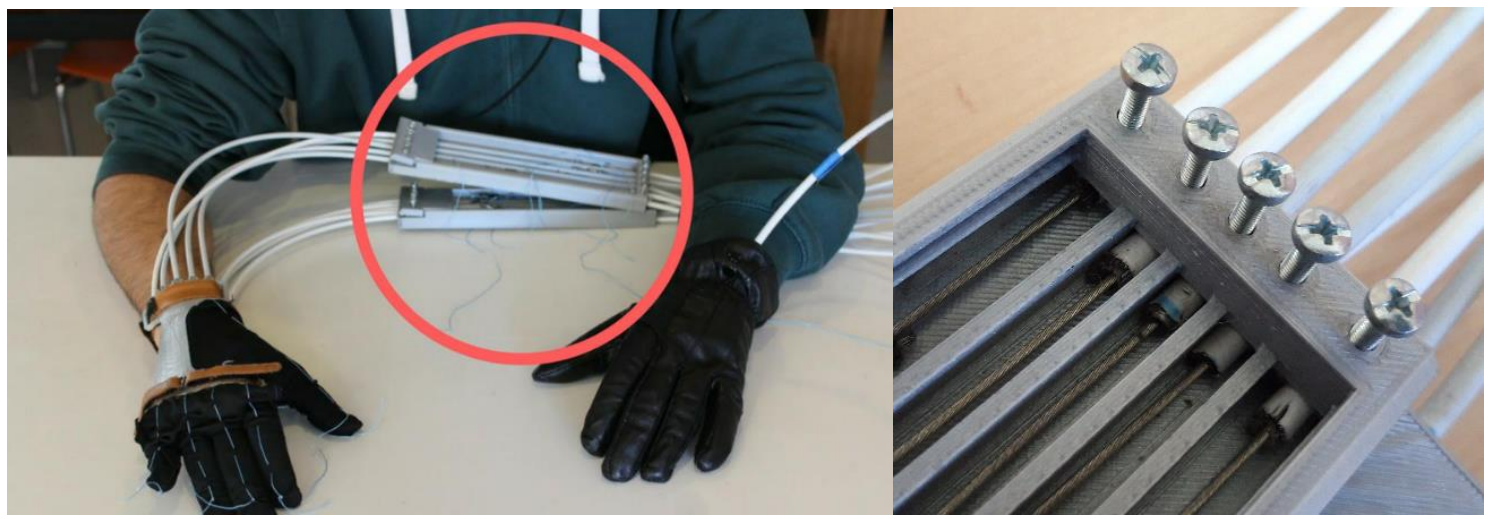

Figure 9. Calibration system (red circle) and a detail of the adjustment system on the right.

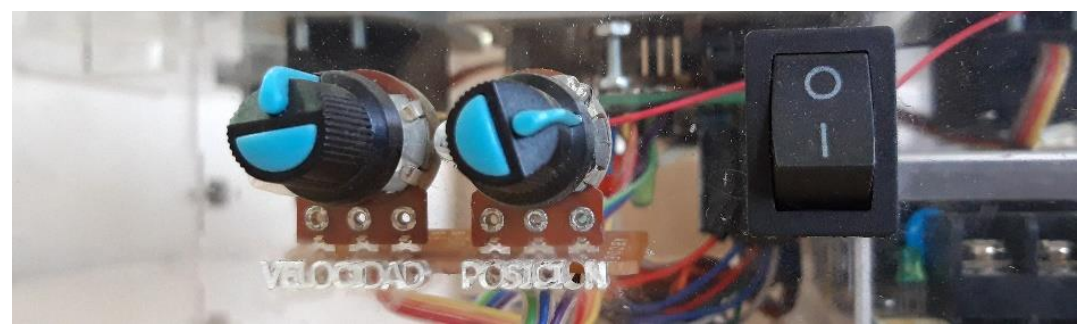

Figure 10. Calibration knobs for speed and position.

The cost of this second prototype was approximately 1.500 US dollars. This cost includes the electronic parts, the case (made in acrylic, cut by laser cutter machine and with 3D printed joints), the transmission system (bicycle cables and $3 \mathrm{~d}$ printed parts) and the student scholarship. Because this project was carried out in the context of an academic work, further costs as space/equipment rental and professional services (medical doctors, supervision from academics) were not considered at this stage. 


\section{CONCLUSIONS AND FUTURE WORK}

The combination of two therapies (mirror and passive exercise) in a low cost robotic system has not been implemented in the field of finger-hand rehabilitation. Theoretically, this new type of combined therapy seems to work very well, according to the feedback received from rehabilitation specialists. However, it still needs design refinements and, more important, it needs to be validated with real patients at a public hospital. If statistical data, collected from these validation tests, show that there are significant improvements in the patient recovery then this proposal will be the starting point for the future design of robotic rehabilitation systems that integrate at least 2 therapies simultaneously.

This work was born in the Autumn Term of 2015, in the context of an undergraduate course in Product Development. In 2017 a student that was part of the original team, continued with the development of this product as part of his final year project. To do so, he worked with an interdisciplinary group having financial support from the University. Later, in 2018, the student got a seed fund to continue working on this robotic system and, because of this work, he was recognised as one of the 100 young influencers in Chile. Additionally, in the same year, the student got the first place in "Falling Walls Labs Chile", an event on breakthroughs in science and society. In November 2018, he presented this project in Falling Walls Germany. Currently, early 2019, the student funded a small start-up company to continue the development process of the presented project.

\section{REFERENCES}

Bouzit, M., Burdea, G., Popescu, G. and Boian, R. (2002), “The Rutgers Master II-new design force-feedback glove”, IEEE/ASME Transactions on Mechatronics, Vol. 7 No. 2, pp. 256-263. http://doi.org/10.1109/TMECH.2002.1011262

Brokaw, E.B., Black, I., Holley, R.J. and Lum, P.S. (2011), "Hand Spring Operated Movement Enhancer (HandSOME): a portable, passive hand exoskeleton for stroke rehabilitation", IEEE Transactions on Neural Systems and Rehabilitation Engineering, Vol. 19 No. 4, pp. 391-399. http://doi.org/10.1109/TNSRE.2011.2157705

Carey, J.R., Durfee, W.K., Bhatt, E., Nagpal, A., Weinstein, S.A., Anderson, K.M. and Lewis, S.M. (2007), "Comparison of finger tracking versus simple movement training via telerehabilitation to alter hand function and cortical reorganization after stroke", Neurorehabilitation and Neural Repair, Vol. 21 No. 3 , pp. 216-232. https://doi.org/10.1177/1545968306292381

Duschau-Wicke, A., Caprez, A. and Riener, R. (2010), "Patient-cooperative control increases active participation of individuals with SCI during robot-aided gait training", Journal Of Neuroengineering and Rehabilitation, Vol. 7 No. 1, p. 43. https://doi.org/10.1186/1743-0003-7-43

Fanin C., Gallina P., Rossi A., Zanatta U. and Masiero S. (2003), "Nerebot: a wire-based robot for neurorehabilitation", 8th International Conference on Rehabilitation Robotics ICORR03, Daejeon, Republic of Korea, New York (NY), IEEE, pp. 23-26.

Feigin, V., Norrving, B. and Mensah, G.A. (2017), "Global burden stroke”, Circulation Research, Vol. 120, No. 3, pp. 439-448. http://doi.org/10.1161/CIRCRESAHA.116.308413

Fischer, H.C., Stubblefield, K., Kline, T., Luo, X., Kenyon, R.V. and Kamper, D.G. (2007), "Hand rehabilitation following stroke: a pilot study of assisted finger extension training in a virtual environment", Topics in Stroke Rehabilitation, Vol. 14 No. 1, pp. 1-12. https://doi.org/10.1310/tsr1401-1

Folgheraiter, M., Gini, G.C. and Vercesi, D.L. (2005), "A glove interface with tactile feeling display for humanoid robotics and virtual reality systems", International Conference on Informatics in Control, Automation and Robotics ICINCO, Barcelona, September 14-17 2005, pp. 353-360.

Goic, A. (2015), "The Chilean Health Care System: The task ahead”, Revista Médica de Chile, Vol. 143 No. 6 , http://doi.org/10.4067/S0034-98872015000600011

Hesse, S., Schulte-Tigges, G., Konrad, M., Bardeleben, A. and Werner, C. (2003), "Robot-assisted arm trainer for the passive and active practice of bilateral forearm and wrist movements in hemiparetic subjects", Archives of Physical Medicine and Rehabilitation, Vol. 84 No. 6, pp. 915-920. http://doi.org/10.1016/S0003-9993(02)04954-7

Hidler, J., Nichols, D., Pelliccio, M. and Brady, K. (2005), “Advances in the understanding and treatment of stroke impairment using robotic devices", Topics in Stroke Rehabilitation, Vol. 12 No. 2, pp. 22-35. https://doi.org/10.1310/RYT5-62N4-CTVX-8JTE

Iqbal, J. and Baizid, K.(2015), "Stroke rehabilitation using exoskeleton-based robotic exercisers: Mini Review", Biomedical Research. Vol. 26 No. 1, pp. 197-201.

Iqbal, J., Tsagarakis, N.G. and Caldwell, D.G. (2011), "Design of a wearable direct-driven optimized hand exoskeleton device" 4th International Conference on Advances in Computer-Human Interactions (ACHI), Gosier, France, pp. 142-6. 
JACE Systems, "JACE H440 hand CPM". Available at http://www.jace-systems.de/produkte/finger.html. Last accessed 16 December 2018

Kamper, D.G., Harvey, R.L., Suresh, S. and Rymer, W.Z. (2003), "Relative contributions of neural mechanisms versus muscle mechanics in promoting finger extension deficits following stroke", Muscle \& Nerve: Official Journal of the American Association of Electrodiagnostic Medicine, Vol. 28 No. 3, pp. 309-318. https://doi.org/10.1002/mus.10443

Kwakkel, G., Kollen, B.J. and Krebs, H.I. (2008), "Effects of robot-assisted therapy on upper limb recovery after stroke: a systematic review", Neurorehabilitation and Neural Repair, Vol. 22 No. 2, pp. 111-121. https://doi.org/10.1177/1545968307305457

Kwakkel, G., Kollen, B.J., van der Grond, J. and Prevo, A.J. (2003), "Probability of regaining dexterity in the flaccid upper limb: impact of severity of paresis and time since onset in acute stroke", Stroke, Vol. 34 No. 9, pp. 2181-2186. https://doi.org/10.1161/01.STR.0000087172.16305.CD

Lambercy, O., Dovat, L., Gassert, R., Burdet, E., Teo, C.L. and Milner, T. (2007), “A haptic knob for rehabilitation of hand function", IEEE Transactions on Neural Systems and Rehabilitation Engineering, Vol. 15 No. 3, pp. 356-366. http://doi.org/10.1109/TNSRE.2007.903913

Langhorne, P., Bernhardt, J. and Kwakkel, G. (2011), "Stroke rehabilitation”, The Lancet, Vol. 377 No. 9778, pp. 1693-1702. http://doi.org/10.1016/S0140-6736(11)60325-5

Lelieveld, M.J., Maeno, T. and Tomiyama, T. (2006), "Design and development of two concepts for a 4 DOF portable haptic interface with active and passive multi-point force feedback for the index finger", $A S M E$ International Design Engineering Technical Conferences and Computers and Information in Engineering Conference, American Society of Mechanical Engineers, Philadelphia, USA, pp. 547-556. http://doi.org/10.1115/DETC2006-99111

Loureiro, R.C., Harwin, W.S., Nagai, K. and Johnson, M. (2011), “Advances in upper limb stroke rehabilitation: a technology push”, Medical \& biological engineering \& computing, Vol. 49 No. 10, p. 1103. http://doi.org/10.1007/s11517-011-0797-0

Lum, P.S., Burgar, C.G., Shor, P.C., Majmundar, M. and Van der Loos, M. (2002), "Robot-assisted movement training compared with conventional therapy techniques for the rehabilitation of upper-limb motor function after stroke", Archives of Physical Medicine and Rehabilitation, Vol. 83 No. 7, pp. 952-959. https://doi.org/10.1053/apmr.2001.33101

Minsal, Ministerio de Salud (2014), "Plan de acción ataque cerebro vascular", Subsecretaría de Salud Pública, División de Control y Prevención de Enfermedades, Departamento de Enfermedades No Transmisibles 2nd Ed.

Motorika, (07 of April 2019),”Advanced upper limb therapy system ReoGo TM". Available at: http://motorika.com/reogo/

Moyano, Á. (2010), "El accidente cerebrovascular desde la mirada del rehabilitador", Revista Hospital Clínico Universidad de Chile, Vol. 21, pp. 348-55.

Nef, T., Guidali, M., Klamroth-Marganska, V. and Riener, R., 2009. “ARMin-exoskeleton robot for stroke rehabilitation”. In World Congress on Medical Physics and Biomedical Engineering, September 7-12, 2009, Munich, Germany, pp. 127-130, Springer, Berlin, Heidelberg. https://doi.org/10.1007/978-3-64203889-1_35

Norouzi-Gheidari, N., Archambault, P.S. and Fung, J. (2012). "Effects of robot-assisted therapy on stroke rehabilitation in upper limbs: systematic review and meta-analysis of the literature". Journal of Rehabilitation Research \& Development, Vol. 49 No. 4. http://doi.org/10.1682/JRRD.2010.10.0210

Ochoa, J.M., Narasimhan, Y.J.D. and Kamper, D.G. (September 2009), "Development of a portable actuated orthotic glove to facilitate gross extension of the digits for therapeutic training after stroke". In Engineering in Medicine and Biology Society, 2009. EMBC 2009. Annual International Conference of the IEEE, pp. 6918-6921. http://doi.org/10.1109/IEMBS.2009.5333630

Paik, Y.R., Kim, S.K., Lee, J.S. and Jeon, B.J. (2014), "Simple and task-oriented mirror therapy for upper extremity function in stroke patients: a pilot study", Hong Kong Journal of Occupational Therapy, Vol. 24 No. 1, pp. 6-12. https://doi.org/10.1016/j.hkjot.2014.01.002

Pomeroy, V., Aglioti, S.M., Mark, V.W., McFarland, D., Stinear, C., Wolf, S.L., Corbetta, M. and Fitzpatrick, S.M. (2011), "Neurological principles and rehabilitation of action disorders: rehabilitation interventions", Neurorehabilitation and Neural Repair, Vol. 25 No. 5 suppl, pp. 33S-43S. https://doi.org/10.1177/1545968311410942

Prange, G.B., Jannink, M.J., Groothuis-Oudshoorn, C.G., Hermens, H.J. and IJzerman, M.J. (2006), "Systematic review of the effect of robot-aided therapy on recovery of the hemiparetic arm after stroke", Journal of Rehabilitation Research \& Development, Vol. 43 No. 2, pp. 171-184. http://doi.org/10.1682/JRRD.2005.04.0076

Rothgangel, A.S., Braun, S.M., Beurskens, A.J., Seitz, R.J. and Wade, D.T. (2011), "The clinical aspects of mirror therapy in rehabilitation: a systematic review of the literature", International Journal of Rehabilitation Research, Vol. 34 No. 1, pp. 1-13. http://doi.org/10.1097/MRR.0b013e3283441e98 
Sarakoglou, I., Tsagarakis, N.G. and Caldwell, D.G. (September 2004), “Occupational and physical therapy using a hand exoskeleton based exerciser". In Intelligent Robots and Systems, Proceedings. 2004 IEEE/RSJ International Conference on Vol. 3, pp. 2973-2978. http://doi.org/10.1109/IROS.2004.1389861

Susanto, E.A., Tong, R.K., Ockenfeld, C. and Ho, N.S. (2015), "Efficacy of robot-assisted fingers training in chronic stroke survivors: a pilot randomized-controlled trial" Journal of Neuroengineering and Rehabilitation, Vol. 12 No. 1, p. 42. doi:10.1186/s12984-015-0033-5

Taheri, H., Rowe, J.B., Gardner, D., Chan, V., Gray, K., Bower, C., Reinkensmeyer, D.J. and Wolbrecht, E.T. (2014), "Design and preliminary evaluation of the FINGER rehabilitation robot: controlling challenge and quantifying finger individuation during musical computer game play", Journal of Neuroengineering and Rehabilitation, Vol. 11 No. 1, p. 10. https://doi.org/10.1186/1743-0003-11-10

Tzafestas, C.S. (2003). "Whole-hand kinesthetic feedback and haptic perception in dextrous virtual manipulation”. IEEE Transactions on Systems, Man, and Cybernetics-Part A: Systems and Humans, Vol. 33 No. 1, pp. 100-113. https://doi.org/10.1109/TSMCA.2003.812600

Wang, J., Li, J., Zhang, Y. and Wang, S. (September 2009), "Design of an exoskeleton for index finger rehabilitation". In Engineering in Medicine and Biology Society, 2009. EMBC 2009. Annual International Conference of the IEEE, pp. 5957-5960. IEEE. http://doi.org/10.1109/IEMBS.2009.5334779

Wege, A. and Hommel, G. (August 2005). "Development and control of a hand exoskeleton for rehabilitation of hand injuries". In Intelligent Robots and Systems, 2005 IEEE/RSJ International Conference on pp. 30463051. http://doi.org/10.1109/IROS.2005.1545506

\section{ACKNOWLEDGEMENTS}

The authors would like to thank Universidad Técnica Federico Santa María (UTFSM), the UTFSM research grant 216.30.1 and the Basal Project 0008 for funding this project. Additionally, we would like to give special thanks to the Hospital de Peñablanca for allowing us to interview/observe patients and use their installations to carry out meetings with the medical staff. 